\title{
Resistência na cidade disciplinar: anarquismo, mulheres e o proletariado como contraponto à construção das cidades ideais no Brasil
}

RAGO, Margareth. Do cabaré ao lar: a utopia da cidade disciplinar: Brasil 1890-1930. 4. ed. São Paulo: Paz e Terra, 2014.

Kauan Willian dos Santos ${ }^{1}$

Analisar a resistência, ou melhor, os diversos tipos de resistências na construção de uma ideologia dominante no período republicano brasileiro foi a tarefa da historiadora e filósofa Margareth Rago na sua presente obra. A autora, professora colaboradora e livredocente do Departamento de História da Universidade Estadual de Campinas (UNICAMP), já é consagrada estudando o controle disciplinar e seus potenciais contrapontos como o feminismo, o anarquismo, a sexualidade e as biografias de personagens responsáveis por condensar os aspectos que explicam essas dinâmicas. Sua dissertação de mestrado, com a orientação do professor Edgard de Decca, intitulada Sem fé, sem lei, sem Rei: liberalismo e experiência anarquista na República, foi publicada como livro pela primeira vez em 1985, intitulado Do cabaré ao lar: a utopia da cidade disciplinar: Brasil 1890-1930, chamando a atenção de diversos historiadores

1 Doutorando em História Social pela Universidade de São Paulo. Email: kauanwillian@usp.br.

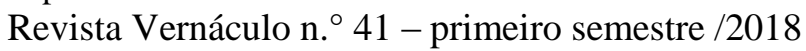

ISSN 2317-4021 
preocupados tanto com o âmbito social como com o cultural. Agora, a estudiosa retoma alguns pontos para a republicação dessa importante referência.

O principal ponto do livro é rever como foi o processo de construção de um projeto da cidade disciplinar no período republicano no Brasil, principalmente nas cidades de São Paulo e Rio de Janeiro, que tinham no higienismo e no positivismo europeu suas principais referências, contando com a nascente burguesia industrial a partir de funcionários públicos, engenheiros e médicos. Nesse quesito, é de se notar que desde a publicação das obras do filósofo francês Michel Foucault, influente da década de 1970 em diante, a temática dos processos disciplinadores da sociedade contemporânea em relação às cidades e aos corpos foi temática recorrente de diversos pesquisadores. ${ }^{2}$ Alguns deles, como Joan Scott, se preocuparam em examinar como alguns indivíduos se contrapuseram a esses discursos e práticas dominadoras. ${ }^{3}$ Mas isso não satisfez completamente a autora em questão, que, nesta obra, não está atenta apenas aos processos individuais ou às práticas discursivas em torno dos processos citados. Rago aborda um grupo social, cultural e político que, dentro da formação da classe operária e importante para sua impulsão nesse período, construiu formas de resistência contra essa ideologia

\footnotetext{
${ }^{2}$ Ver RAGO, Margareth. O efeito-Foucault na historiografia brasileira. Tempo Social, v. 7, p. 67-82, 1995.

${ }^{3}$ SCOTT, Joan. Gender and the politics of history. New York: Columbia University Press, 1988.
}

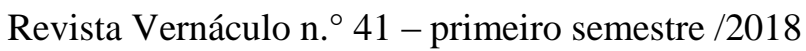

ISSN 2317-4021 
dominante a partir de um imaginário e práticas coletivas: os anarquistas.

Nesse último sentido, foi de muita importância outra referência teórica que gravita a obra, a influência do historiador Edward Thompson. Ao findar a década de 1980, podemos observar a consolidação do estudo das classes trabalhadoras, do qual tal autor foi um dos principais expoentes. Na sua célebre obra A Formação da Classe Operária Inglesa, publicada primeiramente em 1963 na Inglaterra, o autor contextualiza a noção de classe, que, nessa interpretação, não é o resultado natural do desenvolvimento de forças produtivas ou de uma economia funcional. Para Thompson (1987), ainda preocupado com a construção do capitalismo e da luta de classes, tais processos devem ser vistos como resultado de experiências e de seus embates, que ressignificavam e adaptavam culturas anteriores, em relação às forças produtivas e à economia. $\mathrm{O}$ autor ressalta os próprios agentes históricos e elementos como a cultura popular na construção dessa experiência. A formação da classe, para muitos pesquisadores que assumiram sua visão, não pode ser vista apenas pelo nascimento de um partido com representação eleitoral ou pressuposta por algum intelectual ou militante. Desse modo, o movimento anarquista, que não se apresentou como um partido eleitoral e, por isso, foi considerado por muitos pesquisadores como pré-político, na realidade emergiu como objeto de estudo, já que apresentou inúmeras formas de outras propostas como escolas, sindicatos, greves, boicotes e uma nova moral política, social e econômica. Para Margareth Rago,

Revista Vernáculo n. ${ }^{\circ} 41$ - primeiro semestre /2018

ISSN 2317-4021 
[...] os anarquistas e operários em geral se opuseram numa luta ferrenha buscando realizar sua utopia de construção de um novo mundo, mais humano, mais justo, mais livre, onde todos teriam seus direitos de vida assegurados. No campo da educação, no âmbito da produção, na redefinição dos papéis sociais atribuídos a homens, mulheres, crianças, na reestruturação das relações familiares afetivas, na composição de uma nova paisagem espacial, os anarquistas acenaram com propostas que, de certo modo, refletiram os anseios e as esperanças de uma classe negada em todos os momentos de sua vida cotidiana, do trabalho ao lazer, e que sem dúvida se fez num processo de luta, cujas marcas se mantiveram profundas, a despeito de toda tentativa de silenciamento. ${ }^{4}$

Portanto, as práticas anarquistas e a realidade operária são vistas dentro de um embate dialético a partir de uma experiência própria e comum enquanto grupo que tensionava, em resposta às opressões, outros projetos políticos, sociais e culturais.

É necessário sublinhar que nem todos os autores que instrumentalizaram as ideias de Thompson afirmaram tais posições e justamente por isso foram criticados posteriormente. Tais críticos afirmaram que, apesar dos avanços em se compreender as expressões classistas, sob o viés que inclui etnicidade, cultura e representação, muitas visões foram tomadas por proposições sem objetivos e metodologia claros. No caso brasileiro, Marcelo Badaró Mattos nos informa que o fato de ressaltarem apenas o suposto culturalismo de

${ }^{4}$ RAGO, Margareth. Do cabaré ao lar: a utopia da cidade disciplinar: Brasil 18901930. 4. ed. São Paulo: Paz e Terra, 2014. p. 266.

Revista Vernáculo n. ${ }^{\circ} 41$ - primeiro semestre /2018

ISSN 2317-4021 
Thompson mas negligenciarem suas preocupações com os embates e construções classistas e com uma ampliação do marxismo são fatores marcantes e preocupantes, quando pensamos na recepção do autor na historiografia. Portanto, o uso de autores claramente marxistas com outros tidos como pós-estruturalistas se torna confuso para alguns e até de má-fé para outros. ${ }^{5}$

No entanto, apesar das referências de Foucault e Thompson serem usadas na obra, é possível perceber que a autora considera, por um lado, a construção de uma classe em contraposição a outra de forma dialética e, de outro, os discursos e práticas disciplinadoras que perpassavam os grupos operários e anarquistas, incluindo as formas de resistências internas. Desse modo, no período em que a dissertação foi escrita, apenas as referências foucaultianas pareciam responder à reprodução de poderes dentro de grupos considerados livres de opressões.

Nesse caso, é necessário salientar como, de forma original e que fez muitos seguidores, a autora explora a relação constante de desconstrução de poder e opressão contida no anarquismo. Os anarquistas, para a autora, foram o grupo mais poderoso em incitar o universo operário a se contrapor aos discursos disciplinadores que surgiam desde o fim do século XIX, que criavam horários rígidos nas fábricas, separavam os bairros operários dos bairros nobres, defendiam

${ }^{5}$ MATTOS, Marcelo Badaró. E.P. Thompson no Brasil. Outubro. n.14, p. 83-110, 2006.

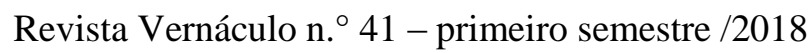

ISSN $2317-4021$ 
regras de comportamento e discursavam teses escrachando a pobreza. Em resposta, os anarquistas difundiam, sobretudo através da imprensa, campanhas para o boicote e as greves visando uma revolução contra a burguesia. Muito importante também era a crítica à separação de habitações para pessoas mais abastadas em contraposição aos operários; criticavam a moral e a educação disciplinadora provinda da política oficial que, para eles, era controlada pelos poderes econômicos vigentes. No entanto, muitas vezes, os próprios reproduziam práticas problemáticas para a construção de um mundo libertário, como, por exemplo, considerar que a função da mulher era ajudar o companheiro dentro de casa, resgatar e manter sua pureza, configurando, no fim, uma opressão contra a mulher, ainda mais a revolucionária e atuante. Apesar disso, a autora mostra que não foi preciso a formulação de uma teoria na década de 1960 ou a ascensão do movimento feminista, após isso, para configurar a resistência contra tais práticas. Dentro do próprio movimento, as mulheres criaram um ideário diferente, lutando contra estruturas de poder internas e externas e, assim, reconfigurando o anarquismo para além do anti-capitalismo, também como feminista.

É essa destreza em capturar as mais diferentes resistências para a construção do anarquismo e sua importância na formação da classe operária que a autora adentra suas fontes incluem a larga imprensa anarquista, atas de congressos, cartas e imagens produzidas pelo movimento, além dos próprios projetos considerados opressores através dos discursos políticos, médicos e da grande imprensa que tinham como

Revista Vernáculo n. ${ }^{\circ} 41$ - primeiro semestre /2018

ISSN $2317-4021$ 
objetivo uma cidade e um operariado ideal e controlado.

No primeiro capítulo, intitulado Fábrica Satânica / Fábrica Higiênica, a autora inicia sua argumentação mostrando e analisando os discursos e práticas que visavam controlar, desde o início do século XX, a forma de trabalho nas capitais industriais. A ideia de uma fábrica higienizada e limpa, com trabalho pontual, rígido e mecânico, estava no ideário da nascente burguesia industrial, tanto para garantir seu poder, como para controlar o grande número de trabalhadores contra possíveis reivindicações. Do outro lado, Rago mostra como foram a propaganda e as ações contra essas medidas, por parte dos anarquistas, que incitavam os trabalhadores a tomarem as fábricas, visando a autogestão e uma vida melhor. No capítulo seguinte, A colonização da mulher, evidenciam-se as medidas e o pensamento dos grupos dominantes, que tentavam impor e difundir gestos e uma cultura para a mulher, julgando as que não escolhiam uma vida próxima ao lar como males sociais, inclusive portadoras de doenças mentais. A autora também adentra como a reverberação desse pensamento era apresentada nos ambientes operários que, por vezes, viam as mulheres supostamente responsáveis pelo lar e pela família como verdadeiras representantes da revolução. Porém, com embates significativos de mulheres que interpretavam os pensamentos e práticas libertárias a seu favor, a autora mostra inúmeras militantes que contrapunham-se a esses poderes através de suas práticas, discutindo nos círculos operários e anarquistas seu valor como revolucionárias e participando ativamente nas greves e manifestações.

Revista Vernáculo n. ${ }^{\circ} 41$ - primeiro semestre /2018

ISSN 2317-4021 
Nesse último sentido, é de se notar que, desde então, muitas pesquisas estão tentando rever o papel das mulheres, que pode ter sido ofuscado nas primeiras análises sobre o movimento operário no Brasil republicano. A análise detida e com a lente reduzida de biografias de personagens e periódicos ajudou a alavancar essa tarefa, que ainda está sendo construída. A autora Samanta Mendes, recente especialista no assunto, defende que a "reconstrução da história de vida dessas mulheres deve levar em conta os ideais e concepções nos quais elas estavam envolvidas, nos quais buscavam explicações para suas vidas e sua militância e sobre as quais as próprias puderam imprimir suas próprias formas de pensar e agir."6

Tal "História vista a partir de baixo" também circula o terceiro capítulo da obra, intitulado A Preservação da Infância, no qual a autora tenta resgatar como foi a resistência das crianças ao trabalho abusivo que era praticado nesse período. Muitas fábricas contratavam as crianças dos bairros operários, pois eram mão de obra mais barata e, do mesmo modo, também criavam medidas para as mesmas serem controladas nesses espaços. Com poucos relatos, já que as próprias crianças não escreveram sua história, a autora vasculha indícios presentes nos jornais operários que mostram como muitas delas fugiam, se revoltavam quebrando máquinas ou mesmo brincavam nos ambientes de trabalho, resistindo, a partir de sua infância, contra as opressões

${ }^{6}$ MENDES, Samanta. As mulheres anarquistas na cidade de São Paulo (1889-1930). Dissertação (Mestrado em História). Universidade Estadual Paulista, Franca - São Paulo, 2010. p. 11.

Revista Vernáculo n. ${ }^{\circ} 41$ - primeiro semestre $/ 2018$

ISSN $2317-4021$ 
impostas.

No último capítulo, A desodorização do Espaço Urbano, a autora conclui sua argumentação mostrando as medidas públicas e pensamentos políticos que visavam separar e controlar os bairros das cidades, criando regiões feitas para os trabalhadores em relação a outras, das classes mais abastadas. A autora salienta, portanto, que a própria construção da cidade contemporânea foi usada como aparato ideológico, também assunto bem atual para os estudos sobre a relação entre patrimônio e ideologia. ${ }^{7}$ Os anarquistas, por outro lado, mostra Rago, fizeram campanhas para ocupar todos os espaços públicos, visando construir uma cidade sem desigualdades sociais a partir de uma nova educação e moral. Desse modo, também, a autora mostra que os anarquistas não podem ser considerados pré-políticos ou provindos de uma teoria não industrial, já que os mesmos estavam inseridos nas problemáticas do capitalismo industrial e de suas medidas políticas e sociais.

Todas as questões apresentadas mostram como a reedição da presente obra ainda é uma grande referência para muitos estudos atuais e em linhas de pesquisas ainda vigentes, visando a construção e resistência de poderes verticais e horizontais, a construção do capitalismo e suas resistências, a história de personagens excluídos como mulheres e os problemas das cidades contemporâneas.

${ }^{7}$ Ver CERASOLI, Josianne. Modernização no Plural: obras públicas, tensões sociais e cidadania em São Paulo na passagem do século XIX para o XX. Tese (Doutorado em História). Universidade Estadual de Campinas, São Paulo, 2004.

Revista Vernáculo n. ${ }^{\circ} 41$ - primeiro semestre $/ 2018$

ISSN 2317-4021 


\section{Referências}

CERASOLI, Josianne. Modernização no Plural: obras públicas, tensões sociais e cidadania em São Paulo na passagem do século XIX para o XX. Tese (Doutorado em História). Universidade Estadual de Campinas, São Paulo, 2004.

MATTOS, Marcelo Badaró. E.P. Thompson no Brasil. Outubro. n. 14, São Paulo, 2006. p. 83-110.

MENDES, Samanta. As mulheres anarquistas na cidade de São Paulo (18891930). Dissertação (Mestrado em História). Universidade Estadual Paulista, Franca - São Paulo, 2010.

RAGO, Margareth. O efeito-Foucault na historiografia brasileira.Tempo Social, v. 7, p. 67-82, 1995.

SCOTT, Joan. Gender and the politics of history. New York: Columbia University Press, 1988.

THOMPSON, Edward. A Formação da Classe Operária Inglesa. Rio de Janeiro: Paz e Terra, 1987.

Recebido em 29/01/2017, aceito para publicação em 10/08/2017

Revista Vernáculo n. ${ }^{\circ} 41$ - primeiro semestre /2018 